$\$=$

\title{
Management and outcome of placenta previa among women attending Khartoum maternity hospitals in Sudan
}

\author{
Siddig Omer Handady ${ }^{1 *}$, Hajar Hassan Sakin ${ }^{2}$, Rania M Omer ${ }^{3}$ \\ ${ }^{l}$ Department of Obstetrical \& Gynecology Imperial Hospital, Khartoum, Sudan \\ ${ }^{2}$ Department of Obstetrical \& Gynecology Royal Hayat hospital, Elkwait \\ ${ }^{3}$ Department of Obstetrical \& Gynecology Police hospital, Khartoum, Sudan \\ *Corresponding author E-mail:bamsi_7@yahoo.com
}

\begin{abstract}
Background: The management of pregnancies complicated by placenta previa is best addressed in terms of the clinical setting: asymptomatic women, women who are actively bleeding and women who are stable after one or more episodes of active bleeding.

Objective: To assess the management and outcome of placenta previa.

Methodology: It was cross-sectional and hospital-basedstudy implemented during a time period of six months (July - December 2012) in Khartoum maternity hospital, and a total of50 women presented with VB diagnosed as placenta previa were selected through convenience sampling method.

Results: Only two patients were deliver vaginally and C/S was done for 48(96.0\%). Regarding outcome 16(32.0\%) of patients were developed bleeding, $5(10 \%)$ of patients were ended by hysterectomy, 2(4\%) developed acute renal failure, one maternal death and $26(52.0 \%)$ of patients were without obvious complications.

Conclusions: The majority of women were undergone C/S and about (90.0\%) their placenta were completely separated, $(4.0 \%)$ left inside and $(6.0 \%)$ left partially.
\end{abstract}

Keywords: Management; Outcome; Placenta Previa.

\section{Introduction}

The prevalence of placenta previa has been recently estimated to be approximately $0.5 \%$ of all pregnancies, and this increase correlates to the elevated cesarean section rate (Kayem \& Keita 2014). Placenta previa is a major cause of maternal morbidity and mortality because of the associated antepartum and intrapartum hemorrhage. Moreover, placenta previa is ssociated with preterm delivery, with the neonatal mortality increasing threefold as a result of prematurity (Rao et al. 2012). Although placenta previa is ssociated with antepartum hemorrhage, massive hemorrhage necessitating preterm cesarean section is not observed in all women with the condition. The ability to predict severe antepartum hemorrhage and emergency cesarean section is critical in the anagement of placenta previa.

An actively bleeding placenta previa is a potential obstetrical emergency. These women s ould be admitted to the Labor and Delivery Unit for maternal and fetal monitoring. The major goals in managing these pregnancies are: achieve and/or maintain maternal hemodynamic stability and determine if cesarean delivery is indicated. The present paper is an attempt to assess how placenta previa was managed. The study had a focus on maternal morbidity and mortality.

\section{Material and Methods}

It was conducted in Khartoum maternity hospital. It crosssectional implemented during a time period of six months (July - December
2012). A probabilistic sample of 50 women diagnosed as placenta previa attended delivery room was the sample size. A questionnaire was designed (annexure) which contain information regarding patient profile, risk factors, management and outcome.Data was entered into SPSS version 16 and analyzed accordingly. The quantitative variables were presented in mean and standard deviation, and qualitative variables were presented in frequency and percentages. Important summary statistics were obtained, and associations were examined using chi-square test. Significance level of 0.05 (i.e. $\mathrm{P}<0.05$ ) was used to determine the significance of associations being examined.

Ethical clearance and approval for conducting this research were obtained from the general manager of the hospital and informed written consent was obtained from every respondent who agreed to participate in the study. Of course, the respondents informed that the study is not associated with experimental or therapeutic intervention, and information were collected from her.

\section{Results}

The mean ages was $35.05 \pm 2.15$ years. The majority of women 16 $(32.0 \%)$ were secondary educated table (1). The mean (SD) of parity was $6.2 \pm 1.2$ table1. Regarding gestational age, the majority 26 $(52.0 \%)$ were at GA (37-38) weeks (table 1$)$.With regard to methods of management done for women included in the study, C/S done for $48(96.0 \%), 43(89.6 \%)$ of $\mathrm{C} / \mathrm{S}$ were not complicated and 5 $(10.4 \%)$ were ended by hysterectomyand regarding complications $9(18.0 \%)$ of patients were developed intra operative bleed- 
ing,7(14.0\%) of patients were developed $\mathrm{PPH}, 5(10 \%)$ of patients were ended by hysterectomy, $2(4 \%)$ developed acute renal failure, one maternal death due to massive bleeding and 26(52.0\%) of patients were without obvious complications.Concerning placenta management, $45(90.0 \%)$ were completely separated, $2(4.0 \%)$ left inside and $3(6.0 \%)$ left partially and about $38(76.0 \%)$ of patients were received blood. table (2).

Table 3 shows the overall complications in relation to party. This trend was statistically significant, as P-value was $<0.05$.Table 4 shows the significance of differences between the mean points of different managementprovided to a different satisfaction group; Tukey HSD test:

The table below shows the one-way analysis of variance (ANOVA) and the post-Hoc test. Basically, the table is telling us that the mean point of "vaginal delivery" is statistically lower than that of "C/S. It also tells us that the mean point of "" of hysterectomy were lower than vaginal deliverybut not statistically significant than the mean points of "C/S" and "blood transfusion.

Table 1: Placenta Previa and Demographic Data

\begin{tabular}{lll}
\hline Variable & Frequency & Percentage \\
\hline Age $<20$ years & 3 & $(06.0 \%)$ \\
20-30 years & 11 & $(22.0 \%)$ \\
$31-40$ years & 21 & $(42.0 \%)$ \\
$>40$ years & 15 & $(30.0 \%)$ \\
Total & 50 & $(100.0 \%)$ \\
Occupation Students & 10 & $(20.0 \%)$ \\
House wife & 28 & $(56.0 \%)$ \\
Employer & 7 & $(14.0 \%)$ \\
Worker & 5 & $(10.0 \%)$ \\
Total & 50 & $(100.0 \%)$ \\
Nationality Sudanese & 44 & $(88.0 \%)$ \\
Ethiopian & 4 & $(08.0 \%)$ \\
Other & 2 & $(04.0 \%)$ \\
Total & 50 & $(100.0 \%)$ \\
Education No education & 9 & $(18.0 \%)$ \\
Primary & 13 & $(26.0 \%)$ \\
secondary & 16 & $(32.0 \%)$ \\
University & 10 & $(20.0 \%)$ \\
Post graduate & 2 & $(04.0 \%)$ \\
Total & 50 & $(100.0 \%)$ \\
Gestational age $<37 w e e k s$ & 15 & $(30.0 \%)$ \\
37-38weeks & 26 & $(52.0 \%)$ \\
39-40weeks & 8 & $(16.0 \%)$ \\
$>40 w e e k s$ & 1 & $(02.0 \%)$ \\
Total & 50 & $(100.0)$ \\
Parity PG & 3 & $(06.0 \%)$ \\
Multiparty & 15 & $(30.0 \%)$ \\
Grand multiparty & 32 & $(64.0 \%)$ \\
Total & 50 & $(100.0)$ \\
\hline & &
\end{tabular}

\section{Discussion}

Compared to the literature which states that (placenta previa increases the risk of antepartum (RR 9.8), intrapartum (RR 2.5), and postpartum hemorrhage (RR 1.9) (Kondoh et al. 2014). For this reason, women with placenta previa are more likely to receive blood transfusions (12 versus 0.8 percent without previa and undergo postpartum hysterectomy, uterine/iliac artery ligation, or embolization of pelvic vessels to control bleeding ( 2.5 versus 0 percent without previa(Yee et al. 2008).The present study agrees with our literature and revealed that $9(18.0 \%)$ of patients were developed intra operative bleeding, $7(14.0 \%)$ of patients were developed PPH, 5(10\%) of patients were ended by hysterectomy, $2(4 \%)$ developed acute renal failure, one maternal death due to massive bleeding and 26(52.0\%) of patients were without obvious complications (Aguirre et al. 2006, Bhide \& Thilaganathan 2004 Lam et al. 2004, Oppenheimer 2007).

Placenta accretes causes considerable maternal morbidity and mortality and is the major indication for emergency peri-partum hysterectomy (Ruparelia \& Chapman 1988). Antenatal confirmation of placenta accretes diagnosis is often difficult. The management is usually a cesarean delivery and hysterectomy, but this approach often causes massive hemorrhage and may cause injury of adjacent organs due to the morbidly adherent placenta. Delayed trans-vaginal removal of the placenta has also been described. Some studies suggested that leaving placenta in situ lowers the risk for subsequent hysterectomy and may hence be an option in cases when emergency hysterectomy is considered too risky or fertility needs to be preserved(Aguirre et al. 2006, Most et al. 2008, Yee et al. 2008). The current study finds that five cases of Placenta accrete, which ended by hysterectomy and in two cases, the placenta was left inside. The maternal mortality rate associated with placenta previa is less than 1 percent in resource-rich countries (Kondoh et al. 2014, Uygur et al. 2014, Walker et al. 2013), but remains high in resource-poor countries where maternal anemia, lack of medical resources, and home births are common.The present study revealed one case of maternal death due to massive post-partum hemorrhage.

Table 2: The Distribution of the Study Population According To the Methods of Management

\begin{tabular}{lll}
\hline Variable & Frequency & Percent \\
\hline Delivery & 2 & \\
VD & 48 & $(04.0 \%)$ \\
C/S & 50 & $(96.0 \%)$ \\
Total & & $(100.0 \%)$ \\
Operation & 43 & \\
Not complicated C/S & 5 & $(89.6 \%)$ \\
Hysterectomy & 50 & $(10.4 \%)$ \\
Total & & $(100.0 \%)$ \\
Placenta management & 45 & \\
Separated & 2 & $(90.0 \%)$ \\
Left inside & 3 & $(04.0 \%)$ \\
Left partially & 50 & $(06.0 \%)$ \\
Total & & $(100.0 \%)$ \\
Blood transfusion & 38 & \\
Yes & 12 & $(76.0 \%)$ \\
No & 50 & $(24.0 \%)$ \\
Total & & $(100.0 \%)$ \\
Complications & 16 & \\
Bleeding & 5 & $(32.0 \%)$ \\
Hysterectomy & 2 & $(10.0 \%)$ \\
ARF & 1 & $(04.0 \%)$ \\
Death & 26 & $(02.0 \%)$ \\
No complications & 50 & $(52.0 \%)$ \\
Total & & $(100.0 \%)$ \\
Placenta accrete & 5 & $(10.0 \%)$ \\
Yes & 45 & $(90.0 \%)$ \\
No & 50 & $(100.0 \%)$ \\
Total & & \\
\hline & &
\end{tabular}

Table 3: Shows A Cross-Tabulation between Parity and Overall Complications:

Overall complications * Parity Cross-tabulation

Count

\begin{tabular}{llllll} 
& & \multicolumn{3}{c}{ Parity } & Total \\
\cline { 3 - 5 } & No complica- & PG & Para & Grandmultipara & \\
tion & 1 & 8 & 17 & 26 \\
Overall & Bleeding & 2 & 5 & 9 & 16 \\
complication & $\begin{array}{l}\text { Hysterectomy } \\
\text { Acute renal }\end{array}$ & 0 & 2 & 3 & 5 \\
& $\begin{array}{l}\text { failure } \\
\text { Total }\end{array}$ & 0 & 0 & 2 & 2 \\
Death & 0 & 0 & 1 & 1 \\
& & 3 & 15 & 32 & 50
\end{tabular}

$$
\mathrm{X} 2=57.326, \mathrm{P} \text {-value }=0.000
$$

Table 4:Shows the Significance of Differences between the Mean Points of Different Management Provided To Different Satisfaction Group (Tukey HSD Test)

\begin{tabular}{lllll}
\hline \multirow{2}{*}{ Overall management } & & $\begin{array}{l}\text { Mean Difference } \\
(\mathrm{I}-\mathrm{J})\end{array}$ & $\begin{array}{l}\text { Std. } \\
\text { Error }\end{array}$ & Sig. \\
\hline & VD & -1.153 & .443 & .073 \\
Type of man- & C/S & $-2.126^{*}$ & .514 & .000 \\
agement & Hysterectomy & -.761 & .461 & .066 \\
& $\begin{array}{l}\text { Blood } \\
\text { transfusion }\end{array}$ & $-1.604^{*}$ & .548 & .030 \\
\hline
\end{tabular}

The mean difference is significant at the 0.05 level. 
A number of observations from this study may be useful in reducing maternal morbidity and mortality associated with placenta previa or other obstetrical emergency of any maternal causes.Maternal mortality and morbidity could be reduced by opening an additional labour and delivery suite and increasing the obstetric services to include surgical delivery (caesarian) in the remotersettlements and anesthetic and blood-transfusion capabilities. We need to improve the availability of comprehensive essential obstetric care.In addition, increasing the capacity and accessibility of local Sudan health-care facilities would benefit management of placenta previa. However, this will only reduce maternal mortality and morbidity if women are able to access services when necessary. Improving accessibility requires addressing the barriers at the first and second level, improving the knowledge of women, their family, and their birth attendants about maternal complications, and enhancing their ability to access care when they decide to seek it.

Women who died due to placenta previa, placenta accretes or other obstetrical emergencies of maternal causes were more likely to have died either in a health-care facility or on their way to one, suggesting that attempts are made to access health care when complications arise.

\section{Conclusion}

Overall, the study showed a positive correlation between placenta previa and increased risk of maternal morbidity and morbidity inform of increase $\mathrm{C} / \mathrm{S}$ rate, caesarean hysterectomy, intra operative bleeding and post-partum hemorrhage. The majority of women underwentC/S and about (90.0\%) their placenta were completely separated, $(4.0 \%)$ left inside and $(6.0 \%)$ left partially.Delayed hysterectomy may be a reasonable strategy in the most severe cases.

\section{References}

[1] Aguirre D, Caiseda D, Correa-Rivas M, Maldonado M, Rodriguez W, Miranda G, Lugo A \& Gandia J (2006): A multidisciplinary approach to surgical management of placenta previa percreta with bladder invasion: a case report. $P R$ Health Sci $J 25,163-165$.

[2] Bhide A \& Thilaganathan B (2004): Recent advances in the management of placenta previa. Curr Opin Obstet Gynecol 16, 447 451. http://dx.doi.org/10.1097/00001703-200412000-00002.

[3] Kayem G \& Keita H (2014): [Management of placenta previa and accreta.]. J Gynecol Obstet Biol Reprod (Paris) 43, 11421160.http://dx.doi.org/10.1016/j.jgyn.2014.10.007.

[4] Kondoh E, Kawasaki K, Kawamura A, Ueda A, Fujita K \& Konishi (2014): Successful management of intraoperative hemorrhage from placenta previa accreta: intrauterine tamponade balloons brought out through the abdominal wall. J Matern Fetal Neonatal Med 27, 309311.http://dx.doi.org/10.3109/14767058.2013.809418.

[5] Lam H, Pun TC \& Lam PW (2004): Successful conservative management of placenta previa accreta during cesarean section. Int $J$ Gynaecol Obstet 86, 3132.http://dx.doi.org/10.1016/j.ijgo.2003.12.009.

[6] Most OL, Singer T, Buterman I, Monteagudo A \& Timor-Tritsch IE (2008): Postpartum management of placenta previa accreta left in situ: role of 3-dimensional angiography. J Ultrasound Med 27, 1375-1380.

[7] Oppenheimer L (2007): Diagnosis and management of placenta previa. J Obstet Gynaecol Can 29, 261-273.

[8] Rao KP, Belogolovkin V, Yankowitz J \& Spinnato JA, 2nd (2012): Abnormal placentation: evidence-based diagnosis and management of placenta previa, placenta accreta, and vasa previa. Obstet Gynecol Surv 67, 503-519.http://dx.doi.org/10.1097/OGX.0b013e3182685870.

[9] Ruparelia BA \& Chapman MG (1988): Occult infiltrating placenta previa percreta: an unusual case highlighting the management problems in a young patient. Int J Gynaecol Obstet 27, 285287.http://dx.doi.org/10.1016/0020-7292(88)90021-5.

[10]Uygur D, Altun Ensari T, Ozgu-Erdinc AS, Dede H, Erkaya S \& Danisman AN (2014): Successful use of BT-Cath((R)) balloon tamponade in the management of postpartum haemorrhage due to placenta previa. Eur J Obstet Gynecol Reprod Biol 181, 223 228.http://dx.doi.org/10.1016/j.ejogrb.2014.08.002.
[11]Walker MG, Allen L, Windrim RC, Kachura J, Pollard L, Pantazi S, Keating S, Carvalho JC \& Kingdom JC (2013): Multidisciplinary management of invasive placenta previa. J Obstet Gynaecol Can 35, 417-425.

[12]Yee YH, Kung FT, Yu PC, Hsu TY \& Cheng YF (2008): Successful conservative management of placenta previa totalis and extensive percreta. Taiwan J Obstet Gynecol 47, 431434.http://dx.doi.org/10.1016/S1028-4559(09)60011-5. 